\title{
Pregnancy complicated with PFAPA (periodic fever, aphthous stomatitis, pharyngitis and cervical adenitis) syndrome: a case report
}

\author{
Kuniaki Ota ${ }^{1,2}$, Joanne Kwak-Kim ${ }^{3 *}$, Toshifumi Takahashi ${ }^{1,2}$ and Hideki Mizunuma ${ }^{2}$
}

\begin{abstract}
Background: Periodic fever, aphthous stomatitis, pharyngitis and cervical adenitis (PFAPA) syndrome has been considered as a childhood syndrome. The underlying etiology of PFAPA syndrome is unclear however, currently considered as auto-immune inflammatory disease. Recently, a few cases of adult-onset of PFAPA syndrome have been reported. However, there is no report about the successful management of pregnancy complicated with PFAPA syndrome.

Case presentation: The patient was a 31-year-old woman who developed recurrent episodes of high fever associated with cervical adenitis, pharyngitis and vomiting started 9 months after a delivery. She was diagnosed with PFAPA syndrome and cimetidine $800 \mathrm{mg} /$ day was initiated. Since then, these symptoms got better. Cimetidine treatment was discontinued since she became pregnant ( 6 weeks of pregnancy). Except one febrile episode at 8 weeks gestation, she did not develop a febrile episode during pregnancy. Peripheral blood Th1/Th2 ratio was decreased from the first trimester to the second trimester of pregnancy. Then again, the ratio was steadily elevated during the third trimester. At 38 weeks, she delivered a live born infant without any complication. Two months after delivery, she developed PFAPA syndrome again and cimetidine treatment was re-initiated. However, febrile episodes were not controlled well, and Th1/Th2 ratio was further elevated compared to pregnancy status. Colchicine $0.5 \mathrm{mg}$ once a day was initiated. Symptoms were diminished and Th1/Th2 ratio was gradually decreased.

Conclusion: There was no case report of pregnancy complicated with PFAPA syndrome, though there were several reports of adult-onset PFAPA cases without pregnancy. The current case may be the first case report of a successful pregnancy complicated with PFAPA. In this case, PFAPA symptoms were ameliorated during pregnancy, but reappeared after delivery. We speculate that PFAPA syndrome, a Th1 type immune disorder, might be improved due to the Th1 to Th2 shifting, which was induced by pregnancy. It is necessary to investigate further about PFAPA syndrome with pregnancy and Th1/Th2 immune responses in the future.
\end{abstract}

Keywords: PFAPA, Pregnancy, Th1/Th2, Adult onset, Periodic fever, Aphthous stomatitis, Pharyngitis, Cervical adenitis

\footnotetext{
* Correspondence: joanne.kwakkim@rosalindfranklin.edu

${ }^{3}$ Reproductive Medicine and Immunology, Department of Obstetrics and

Gynecology, Chicago Medical School, Rosalind Franklin University of

Medicine and Science, 830 West End Court, Suite 400, Vernon Hills, IL 60061,

USA

Full list of author information is available at the end of the article
}

(c) The Author(s). 2018 Open Access This article is distributed under the terms of the Creative Commons Attribution 4.0 International License (http://creativecommons.org/licenses/by/4.0/), which permits unrestricted use, distribution, and reproduction in any medium, provided you give appropriate credit to the original author(s) and the source, provide a link to the Creative Commons license, and indicate if changes were made. The Creative Commons Public Domain Dedication waiver (http://creativecommons.org/publicdomain/zero/1.0/) applies to the data made available in this article, unless otherwise stated. 


\section{Background}

PFAPA (periodic fever, aphthous stomatitis, pharyngitis and cervical adenitis) syndrome which was first reported in 1987, is the most common autoimmune inflammatory fever disorder in childhood worldwide [1]. It is characterized by predictably periodic high fever lasting for approximately 4 days (ranges 2 to 7 days) and associated with at least one of three clinical symptoms, such as pharyngitis, cervical adenitis and aphthous stomatitis [2]. The underlying etiology of the disease is still unknown, and the diagnosis is made with the clinical criteria proposed by Thomas et al. [2]; 1) Periodic fevers with an early age of onset ( $<5$ years of age), 2) Symptoms in the absence of upper respiratory tract infection with at least 1 of the following clinical signs: a) aphtous stomatitis, b) cervical lymphadenitis, c) pharyngitis, 3) Exclusive of cyclic neutropenia, 4) Completely asymptomatic interval between episodes, 5) Normal growth and development. Furthermore, PFAPA is required to exclude other diseases of recurrent fevers in childhood, such as malignancies, autoimmune and infectious disease. Genetic variants of the innate immune system, such as familial Mediterranean fever (FMF), TNF receptor-associated periodic syndrome (TRAPS), mevalonate kinase deficiency (MKD) and cryopyrin-associated periodic syndromes (CAPS) are also included as the differential diagnosis since PFAPA syndrome is currently supposed the pathogenesis of abnormal host immune response [3]. To date, some researchers reported that adult-onset of PFAPA syndrome, though PFAPA syndrome is basically pediatric disease and usually settles in adolescence $[4,5]$.

We would like to present a case of successful pregnancy complicated with PFAPA syndrome. We believe this is the first report of pregnancy complicated with PFAPA, since PFAPA primarily affects preschool-age children [6] and is rarely occurred in adults [7].

\section{Case presentation}

The patient was a healthy 31-year-old woman who had an uneventful delivery of a live born infant at term 4 years ago. Nine months after the delivery, she developed recurrent episodes of high fever $\left(39^{\circ} \mathrm{C}\right)$ followed by cervical adenitis, pharyngitis and vomiting. A disease-free interval, which ranges 4 to 8 weeks, was observed between the periodic fever episodes, and a menstrual cycle was not related to the onset of a febrile episode.

Elevated C-reactive protein (peak value of $13.9 \mathrm{mg} / \mathrm{dL}$ ) was noticed. Other laboratory studies, including immunoglobulin levels, serum complement level, immuno-phenotypic characterization of lymphocytes, HIV, CMV and EBV serology, and antinuclear antibodies, were negative. Genetic tests for genomic DNA from whole blood were conducted to exclude FMF, TRAPS,
MKD and CAPS and all were negative. Cyclic neutropenia was excluded by serial neutrophil counts.

Her PFAPA symptoms disappeared spontaneously within 5 days without antibiotic treatment and the elevated CRP level became normal in 10 days from the first day of fever. Finally, PFAPA syndrome was diagnosed according to the Padeh's criteria, which are not restricted to the age of onset [8]. To prevent future febrile episodes, cimetidine $400 \mathrm{mg}$ twice daily was started, and $60 \mathrm{mg}$ of intravenous prednisolone was given during a febrile attack. During the subsequent febrile episodes, PFAPA symptoms were lessened. After 8 months passed, she became pregnant and quit cimetidine at the 6th week of gestation by herself. She then developed only one febrile episode at 8th week of gestation without any subsequent febrile episode during pregnancy, possibly due to altered maternal immunity with advanced pregnancy.

T helper (Th)1/Th2 cell ratios were analyzed every $2 \sim$ 6 weeks during pregnancy (Fig. 1). IFN-gamma/ IL-4 producing $\mathrm{CD} 3+/ \mathrm{CD} 4+\mathrm{T}$ helper cell ratios were elevated during the first trimester. During the second trimester, Th1/Th2 ratios were decreased. CRP remained in the normal ranges during entire pregnancy. Whereas Th1/Th2 ratios were increased gradually even without a febrile episode during the third trimester. At 38 weeks, she developed a premature rupture of membrane and delivered a normal healthy male infant, weighing $2873 \mathrm{~g}$. The Apgar scores (1 and $5 \mathrm{~min}$ ) were 9 and 10 respectively. Two months after delivery, she developed an episode of high fever associated with cervical adenitis, pharyngitis and vomiting as she did prior to pregnancy. Cimetidine was re-initiated. Th1/Th2 ratio was 25.5 (Fig. 1). Febrile episodes became worse in severity and frequency and Th1/Th2 ratio was further elevated to 33.4 one month later. Colchicine $0.5 \mathrm{mg}$ once a day was added. Th1/Th2 ratio started to decrease gradually (Fig. 2). Currently, febrile episodes remain shorter and milder.

\section{Discussion and conclusions}

A case of pregnancy complicated with PFAPA syndrome has not been reported despite some reported adult-onset cases [7]. Although the exact pathogenesis of PFAPA has yet to be elucidated, it is considered as a polygenic autoinflammatory disease in which a microbial trigger might give rise to the activation of innate immune system and recruitment of activated $\mathrm{T}$ cells in a susceptible host, leading to Th1 driven immune responses [9]. On the other hand, the predominant Th2-type immunity has been observed during normal pregnancy. Maternal tolerance toward fetal allo-antigens was explained by the predominant Th2-type immunity during pregnancy for protecting the fetus from maternal Th1-immunity [10]. 


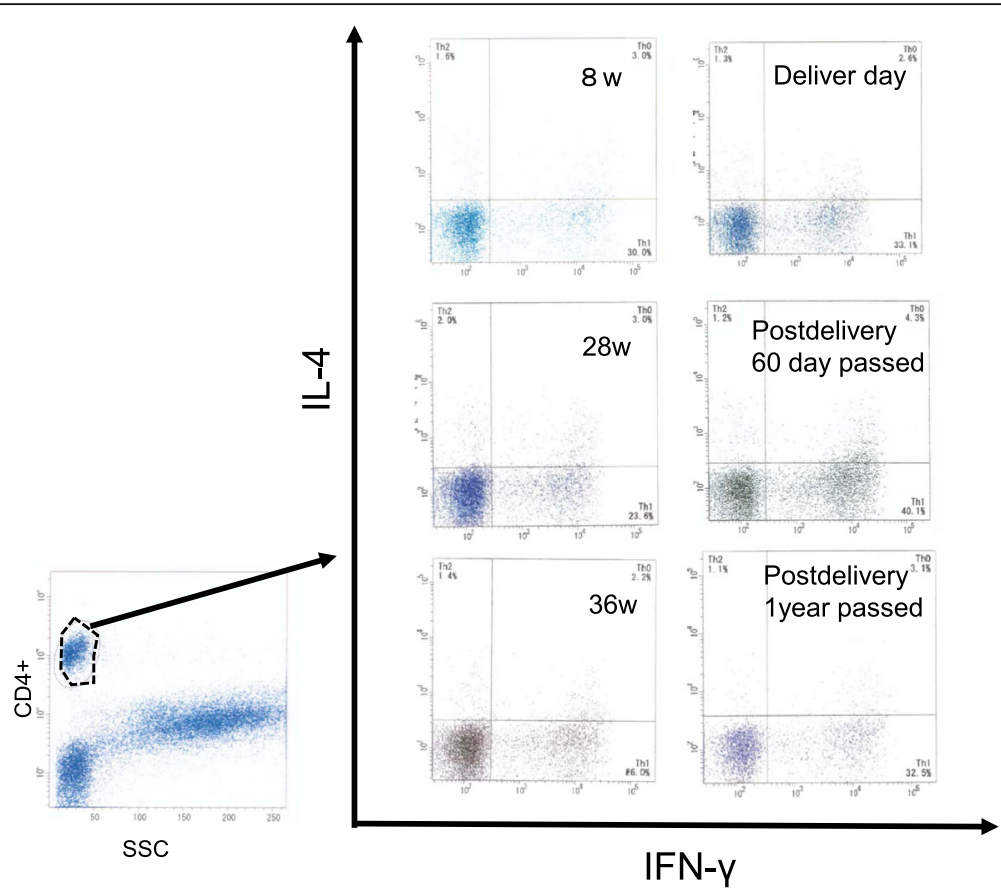

Fig. 1 Th1/Th2 cell ratio (IFN-y/LL-4 T helper cell ratio) was analyzed by flow cytometric analysis. An acquisition gate was established based on CD4 staining and side scatter (SCC) which included peripheral blood mononuclear cells (left). Dot plot analysis of IFN- $\gamma$ and IL-4 expressing CD4 ${ }^{+}$ T cells from the patient. Numbers indicate percent gated cells (right)

During normal pregnancy, Th1/Th2 ratio increases transiently during implantation period, and then decreases after implantation is over. During the third trimester, Th1/Th2 ratio increases for the preparation of parturition. Persistently increased Th1/Th2 ratios have been associated with multiple implantation failures and repeated pregnancy losses $[11,12]$. In this case, Th1/Th2 ratio was elevated during the early first trimester of pregnancy. However, she could succeed in pregnancy and deliver despite the predominant Th1-type immunity which is harmful to pregnancy maintenance. We speculate that PFAPA by Th1 immune disorder might be

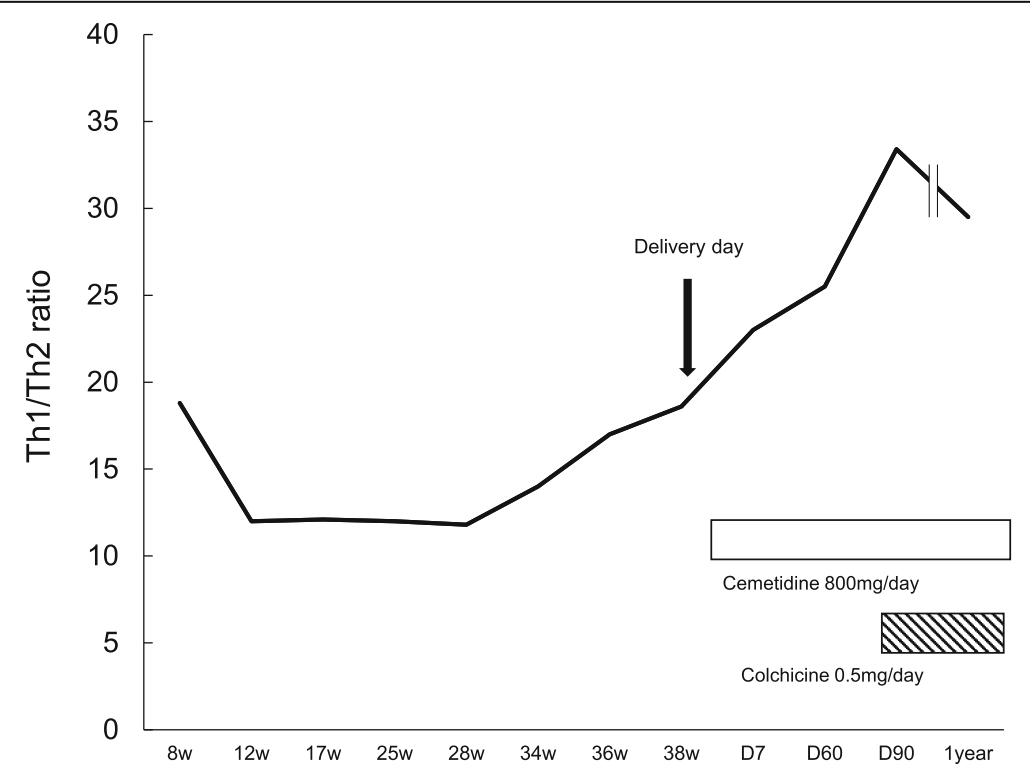

Fig. 2 Time course plot of Th1/Th2 cell ratios (IFN-y/LL-4 Thelper cell ratio) from early pregnancy to postpartum 1 year. The white box indicates the period of cimetidine treatment and the slant bow indicates the period of colchicine treatment 
ameliorated during the second trimester of pregnancy possibly due to the predominant Th2 immunity established during pregnancy. Furthermore, pregnancy complicated with PFAPA can be treated as normal perinatal course since symptoms are relieved by shifted Th2 immunity. It is necessary to pay sufficient attention because febrile episodes are rapidly exacerbated after parturition.

\section{Abbreviations}

CAPS: Cryopyrin-associated periodic syndromes; CD: Cluster of differentiation; CMV: Cytomegalovirus; CRP: C-reactive protein; DNA: Deoxyribonucleic acid; EBV: Ebstein-Barr virus; FMF: Familial Mediterranean fever; HIV: Human immunodeficiency virus; IFN: Interferon; IL: Interleukin; MKD: Mevalonate kinase deficiency; PFAPA: Periodic fever, aphthous stomatitis, pharyngitis, and cervical adenitis; Th1/Th2: T helper 1/T helper 2; TRAPS: TNF receptorassociated periodic syndrome

\section{Availability of data and materials}

The datasets used and/or analyzed during the current study are available from the corresponding author on reasonable request.

\section{Authors' contributions}

$\mathrm{KO}$ designed the study, performed laboratory experiment, analyzed and interpreted the data and prepared the manuscript. JKK contributed the study design and manuscript preparation. $T$ and $\mathrm{HM}$ contributed the data collection and interpretation. All authors read and approved the final manuscript.

\section{Ethics approval and consent to participate}

Not applicable.

\section{Consent for publication}

Written informed consent for publication of the clinical details and/or clinical images was obtained from the patient. A copy of the consent form is available for review by the Editor of this journal.

\section{Competing interests}

The authors declare that they have no competing interests.

\section{Publisher's Note}

Springer Nature remains neutral with regard to jurisdictional claims in published maps and institutional affiliations.

\section{Author details}

'Department of Obstetrics and Gynecology, School of Medicine, Fukushima Medical University, 1-Hikarigaoka, Fukushima 960-1247, Japan. ²Fukushima Medical Center for Children and Women, School of Medicine, Fukushima Medical University, 1-Hikarigaoka, Fukushima 960-1247, Japan. ${ }^{3}$ Reproductive Medicine and Immunology, Department of Obstetrics and Gynecology, Chicago Medical School, Rosalind Franklin University of Medicine and Science, 830 West End Court, Suite 400, Vernon Hills, IL 60061, USA.

Received: 21 February 2018 Accepted: 25 May 2018

Published online: 04 June 2018

\section{References}

1. Marshall GS, Edwards KM, Butler J, Lawton AR. Syndrome of periodic fever, pharyngitis, and aphthous stomatitis. J Pediatr. 1987;1 10(1):43-6.

2. Thomas KT, Feder HM Jr, Lawton AR, Edwards KM. Periodic fever syndrome in children. J Pediatr. 1999;135(1):15-21.

3. Stojanov S, Hoffmann F, Kery A, Renner ED, Hartl D, Lohse P, Huss K, Fraunberger P, Malley JD, Zellerer $S$, et al. Cytokine profile in PFAPA syndrome suggests continuous inflammation and reduced antiinflammatory response. Eur Cytokine Netw. 2006;17(2):90-7.

4. Cavuoto M, Bonagura VR. Adult-onset periodic fever, aphthous stomatitis, pharyngitis, and adenitis. Allergy Asthma Immunol. 2008;100(2):170.

5. Colotto M, Maranghi M, Durante C, Rossetti M, Renzi A, Anatra MG. PFAPA syndrome in a young adult with a history of tonsillectomy. Internal medicine (Tokyo, Japan). 2011;50(3):223-5.
6. Vigo G, Zulian F. Periodic fevers with aphthous stomatitis, pharyngitis, and adenitis (PFAPA). Autoimmun Rev. 2012;12(1):52-5.

7. Padeh S, Stoffman N, Berkun Y. Periodic fever accompanied by aphthous stomatitis, pharyngitis and cervical adenitis syndrome (PFAPA syndrome) in adults. The Israel Medical Association journal : IMAJ. 2008;10(5):358-60.

8. Padeh S, Brezniak N, Zemer D, Pras E, Livneh A, Langevitz P, Migdal A, Pras M, Passwell JH. Periodic fever, aphthous stomatitis, pharyngitis, and adenopathy syndrome: clinical characteristics and outcome. J Pediatr. 1999; 135(1):98-101.

9. Kraszewska-Glomba B, Matkowska-Kocjan A, Szenborn L. The pathogenesis of periodic fever, Aphthous stomatitis, pharyngitis, and cervical adenitis syndrome: a review of current research. Mediat Inflamm. 2015;2015:563876.

10. Saito S, Nakashima A, Shima T, Ito M. Th1/Th2/Th17 and regulatory T-cell paradigm in pregnancy. Am J Reprod Immunol. 2010;63(6):601-10.

11. Kwak-Kim J, Park JC, Ahn HK, Kim JW, Gilman-Sachs A. Immunological modes of pregnancy loss. Am J Reprod Immunol. 2010;63(6):611-23.

12. Kwak-Kim JY, Chung-Bang HS, Ng SC, Ntrivalas El, Mangubat CP, Beaman $\mathrm{KD}$, Beer AE, Gilman-Sachs A. Increased T helper 1 cytokine responses by circulating $T$ cells are present in women with recurrent pregnancy losses and in infertile women with multiple implantation failures after IVF. Hum Reprod. 2003;18(4):767-73.

\section{Ready to submit your research? Choose BMC and benefit from:}

- fast, convenient online submission

- thorough peer review by experienced researchers in your field

- rapid publication on acceptance

- support for research data, including large and complex data types

- gold Open Access which fosters wider collaboration and increased citations

- maximum visibility for your research: over $100 \mathrm{M}$ website views per year

At BMC, research is always in progress.

Learn more biomedcentral.com/submissions 